This is an electronic reprint of the original article. This reprint may differ from the original in pagination and typographic detail.

Author(s): Ojala, Arto

Title: $\quad$ Software Renting in the Era of Cloud Computing

Year: $\quad 2012$

Version:

Please cite the original version:

Ojala, A. (2012). Software Renting in the Era of Cloud Computing. In IEEE Fifth International Conference on Cloud Computing (pp. 662-669). IEEE. IEEE International Conference on Cloud Computing. https://doi.org/10.1109/CLOUD.2012.71

All material supplied via JYX is protected by copyright and other intellectual property rights, and duplication or sale of all or part of any of the repository collections is not permitted, except that material may be duplicated by you for your research use or educational purposes in electronic or print form. You must obtain permission for any other use. Electronic or print copies may not be offered, whether for sale or otherwise to anyone who is not an authorised user. 


\title{
Software Renting in the Era of Cloud Computing
}

\author{
Arto Ojala \\ Department of Computer Science and Information Systems \\ University of Jyväskylä \\ Jyväskylä, Finland \\ arto.k.ojala@jyu.fi
}

\begin{abstract}
In the new era of computing, software can be sold and delivered as a cloud service, and software renting has become as a strategic tool to compete in the market. Software renting has several advantages from the customer's point of view. However, for software providers it is challenging to ensure a profitable revenue stream when a license fee is replaced by a periodic rental fee. In this study, software renting was found to help the case firms to differentiate themselves from competitors; it also increased their competitive advantage by making the software available for a larger customer group. However, the negotiating power of larger customers impacted on software pricing, rental agreements, and the revenue model.
\end{abstract}

Keywords- Software renting, competitive strategy, cloud computing, SaaS

\section{INTRODUCTION}

Software renting may give more economic benefits than other revenue models [4]. However, although software renting is becoming more frequent in the new era of computing, in which software is delivered via the Softwareas-a-Service (SaaS) model, little is known about the advantages and disadvantages of software renting. In addition, most of the existing literature on software renting uses economic modeling to analyze the benefits of software renting $[3,4,9,26]$. I acknowledge the importance of these studies, but see a need for real-life cases in elucidating the strategic reasons that drive software firms to rent their software applications, in preference to the other revenue models available (see e.g. [4]).

As software products belong to the category of information goods, they can be sold via several revenue models. In most cases, copyright of the software belongs to the producer. Thus, the software is licensed to the customer, and the license limits the usage of the software so that the licensee cannot resell, modify, or re-rent the software. The common ways to sell the software are by selling a single license ${ }^{1}$ for a single user or machine, or by selling a license to use the software in a certain number of processors [7]. In addition to the initial license fee, customers commonly have to pay a maintenance fee, which includes technical support and version updates. Other possible revenue models are, for example, (i) pay-per-use, which involves charging the

Here I use "traditional licensing" to refer to the situation in which a customer buys a software license for a single user or a certain number of processors. customer according to the metered usage of the software, (ii) freemium, in which the software is given for free, and the revenue comes (for instance) from maintenance costs, (iii) advertising-based models, in which the revenue typically comes from selling advertisements included in the software. However, in this paper, I shall focus on the type of software rental in which the customer pays a negotiated subscription fee with a time limitation; thus the software is licensed for use during a certain time period $[1,4]$.

The rapid growth of cloud computing has opened up new possibilities for software renting. In the SaaS model, the software is hosted in the data center of a service provider or third party, and delivered to customers via the Internet as a service. Since the software is used as a service, without physical installation in the customer's computers, SaaS is well suited to software renting. However, as noted by Armbrust et al. [1], most of the studies focusing on cloud computing have looked at the benefits from the customer's point of view, neglecting the possible benefits for the software vendor.

The existing literature explains the benefits of rental related to durable goods [8]. However, software products are different from other products that are commonly rented such as cars, DVDs, or apartments. In addition, there have been calls for a better understanding of revenue models in the software business in general $[10,22]$ and especially in relation to software renting $[3,4,26]$. From these considerations, this article contributes to current knowledge in the following ways: (i) it reveals some of the competitive advantages and disadvantages of software renting from the software vendor's point of view, with reference to the competitive theory of Porter $[19,21]$, (ii) it builds on previous work using economic modeling in relation to software renting $[3,4,9,26]$, and (iii) it contributes to an understanding of pricing strategies in software renting. The following research questions were addressed:

1) What are the benefits of software renting?

2) What are the challenges in software renting?

3) What pricing strategies are used in software renting?

\section{LITERATURE REVIEW}

In this section, I shall first present cloud computing and the SaaS model. Thereafter, I shall introduce the economics of renting in general, then software renting from the strategic point of view. I shall include ideas from economic theories $[2,8]$ related to renting, and touch on Porter's $[19,21]$ theory of strategic competition. At the end of the section, I shall 
summarize the key findings and discuss the motivation for this article.

\section{A. Cloud computing and SaaS}

In cloud computing, users obtain access to computing resources, storage space, and software applications via the Internet as a service. Cloud computing includes three service layers. These consist of (i) Infrastructure as a Service (IaaS), which provides computation and storage capacity, (ii) Platform as a Service (PaaS), which provides software development tools plus an application execution environment, and (iii) SaaS, which provides applications on top of PaaS and IaaS $[1,11]$. Thus, cloud computing refers to the provision of computing capacity, storage capacity, and applications as a service across the Internet. The International Data Corporation (IDC) defines cloud computing as "consumer and business products, services and solutions delivered and consumed in real-time over the Internet" [5].

The data center hardware and software forming a "cloud" can be divided into a public cloud, a private cloud, and a hybrid cloud. In a public cloud, a software vendor uses his/her own or a third party's cloud infrastructure (data center) to offer SaaS for customers on demand. A private cloud involves the customer's internal data center, with the software being installed and used in a centralized manner within the organization; in this case the software is not made publicly available $[1,14]$. In the case of a hybrid cloud, a firm using a private cloud may, for example, offload part of the workload onto a public cloud, and in that way acquire more computing capacity [14].

SaaS refers to the provision of software applications over the Internet. Hence, customers have online access to the software when it is needed instead of having it permanently installed on their own computers. This reduces costs, since the high initial costs of a software license can be replaced by software rental or pay-per-use models [3]. SaaS also ensures that the latest version of the software is in use without the continuous installation of updates. In addition, because the software is executed on a service provider's server, it frees users from worrying about the technical specification of the computer or the data storage capacity $[11,27]$.

\section{B. The economics of renting}

Renting is a widely studied topic in economics literature. The benefits of renting as compared to other selling models have been studied using transaction cost theory. Flath [8, 247] defines renting (or leasing) as "a contractual arrangement for trading the rights to temporary use of an object, but not the right to all possible future use." Thus, in a rental agreement, a customer does not get the full ownership rights over the object rented, as distinct from ownership following purchase. However, there are always trade-offs between the benefits of full ownership and those of "partial ownership" - i.e. renting. From the customer's point of view, these benefits are related to the characteristics of the product and the time period needed for usage of the product. In the words of Flath [8, 249], “The shorter is one's expected tenure of use of a good, the greater are the transacting cost gains to his leasing it rather than purchasing it outright."

Renting decreases transaction costs related to identifying, assuring, and maintaining quality, and the cost of searches $[3,4,8]$. Renting can also increase the positive network externality effect [13], owing to the lower initial costs compared to purchasing. The low costs increase the number of buyers, and consequently increase the information available in the market regarding the product. Overall, this decreases customers' search costs, and makes the product well known in the market [4, 20]. Increased consumption also helps in the processes of product development, as the producer learns efficient production and management techniques [4].

In software rental, the customer pays a negotiated subscription fee. There is a time limitation such that the software license is for a fixed period, irrespective of usage [1, 23]. Choudhary et al. [4] list four reasons why the customer may rent software in preference to buying it, as follows: (i) the software is for use in a short-term project, (ii) a customer may simply want to gain experience of using the software, (iii) a customer wants to test and evaluate the usability of the software, or (iv) a customer wants to avoid negative network externality. Choudhary et al. [4] also found that software renting benefited both the software vendor and the customer by providing cost savings for customers, with higher profits also for software vendors. In a subsequent study, Choudhary [3] has argued that software renting also increases the quality of the software. Software renting lessens the customers' need to have their own IT personnel and IT infrastructure. This decreases the total cost of ownership and reduces hidden costs. According to Waters [27], the hidden costs in traditional software licensing can increase a firm's IT budget by as much as 80 percent.

\section{Software rental as a competitive strategy}

In his works on competitive strategy, Porter [19, 21] presents five forces that shape industrial competition, namely (i) the threat of new entrants, (ii) the bargaining power of buyers, (iii) the bargaining power of suppliers, (iv) the threat of substitute products or services, and (v) rivalry among existing competitors. Renting can be seen as a strategy to compete in the market on the basis of the positive impact of the rental on switching costs. According to Porter [21, 81] "switching costs are fixed cost that buyers face when they change suppliers." Switching costs arise, for instance, when a buyer changes to an alternative product, with the buyer then being obliged to train employees to use the product. These costs can be high, especially if a firm has to invest heavily in specialized equipment [21] or product platforms. If renting ties the user to some specific platform, for example the Windows operating system, it increases the switching costs for consumers. However, Choudhary [3] found that in software renting, switching costs are relatively low, and this makes it easy to customers to change a software vendor if the quality/functionality of the software is not at the appropriate level.

Low switching costs in software renting may also increase the negotiating leverage of customers related to the 
bargaining power of buyers. The negotiating leverage of customers is also higher if the products are highly standardized. In this case, customers can always find an alternative product, and they can invite suppliers to tender against each other [21]. Thus, if a software vendor is offering standardized products with a low switching cost, customers have more power to force prices down. According to Porter [21] firms can avoid this situation by developing specialized products with high switching costs.

The threat of substitutes may also impact on software rental as a strategic choice. A substitute is a product that "performs the same or a similar function as an industry's product by a different means" [21, 84]. The threat of a substitute is high if a new product offers better value at a more attractive price than the older one. Software rental and SaaS can be seen as substitutes for traditional software licensing and software delivery, since they can offer attractive pricing compared to traditional licensing, with a low switching cost.

Rivalry among existing competitors impacts on prices. According to Porter [21], rivalry may decrease prices, for example (i) if the products are similar and there are low switching costs for customers, or (ii) if the product is perishable. As discussed above, switching costs in software renting may be relatively low. Software products are also perishable, as their product life cycle is relatively short [16] - in other words, there is an ongoing need for new software updates or new versions.

\section{Summary}

As the current literature indicates, software renting following the SaaS model brings several benefits. However, the literature mainly focuses on the benefits for the customer, and the literature on the software vendor's point of view is almost non-existent. In addition, there seems to be a lack of empirical research in this field, since the literature mostly focuses on economic modeling without any empirical background. For these reasons, I shall examine the benefits of software renting for the vendor via an empirical case study. This is important, since in SaaS the promise of low cost software for customers is, on the face of it, disadvantageous for software vendors [17]. The problems involve how to ensure a profitable revenue stream when an initial license fee is replaced by a usage-based fee.

\section{METHODOLOGY}

The research method selected for this study covered a real-life environment in which there was a decision-making process related to revenue models. Thus, the method should be able to cover human actions, enable the in-depth investigation of the complex phenomena, and capture causeand-effect relationships. With all this in mind, I used a multiple case study methodology similar to the approaches presented by Eisenhardt [6] and Yin [28]. Hence, the aim is find the reasons behind a certain behavior, not generalize the findings.

The research setting for this study consisted of five software firms (see Table 1) who acted as SaaS providers. Since the sample used will necessarily influence the results of the study [15], I used multiple criteria to select the cases. Three of the firms were dealing with a national cloud software program in Finland, while two firms were contacted on the basis of the author's knowledge of the industry. Thus, the most important selection criterion was good access to the required information, as recommended by Stake [24]. The personal-contact aspect increased mutual trust between the researcher and the persons interviewed in the case firms, and consequently facilitated the collection of accurate information. Note, however, that the selection of cases cannot be based solely on good access to information, and that the theoretical perspective must also be also taken into account [6]. In terms of theoretical considerations, the following aspects were seen as relevant: (i) the case firms were developing their software for different industries, (ii) the sample included both relatively old firms and recently established firms, and (iii) three of the firms also had traditional software licenses available for their software. This kind of coverage is important for studies when the sample of firms is small [25], the general aim being to include "polar types" of research sites [18].

TABLE I. OVERVIEW OF THE CASE FIRMS.

\begin{tabular}{|c|c|c|c|}
\hline Firm & $\begin{array}{c}\text { Year of } \\
\text { establishment }\end{array}$ & Product & Target industry \\
\hline A & 1998 & $\begin{array}{l}\text { Planning and } \\
\text { optimization } \\
\text { software for } \\
\text { telecom operators }\end{array}$ & $\begin{array}{c}\text { Telecom operators, } \\
\text { Component } \\
\text { manufacturers and } \\
\text { service providers } \\
\text { for telecom } \\
\text { networks }\end{array}$ \\
\hline $\mathrm{B}$ & 2000 & Gaming platform & Game players \\
\hline $\mathrm{C}$ & 2006 & $\begin{array}{l}\text { Risk management } \\
\text { software for the } \\
\text { financial sector }\end{array}$ & $\begin{array}{c}\text { Bank and financing } \\
\text { sector }\end{array}$ \\
\hline $\mathrm{D}$ & 2008 & $\begin{array}{c}\text { Entitlement } \\
\text { management } \\
\text { software }\end{array}$ & $\begin{array}{l}\text { Large and medium- } \\
\text { sized corporations }\end{array}$ \\
\hline $\mathrm{E}$ & 2006 & $\begin{array}{l}\text { Interactive 3D } \\
\text { sales software }\end{array}$ & $\begin{array}{l}\text { Furniture chains } \\
\text { and furniture } \\
\text { manufacturers }\end{array}$ \\
\hline
\end{tabular}

I used multiple sources of information to gather data on each case firm. The main form of data collection was indepth interviews. Altogether, I conducted 3-8 interviews per firm, each lasting 45-90 minutes. Thus, altogether 23 semistructured open-ended interviews were conducted for this study. The interviewees consisted of Chief Executive Officers (CEOs), sales managers, vice presidents, members of the board of directors, and software engineers. The interviews with the CEOs were the main source of information. During the first interview, I collected general information about the firm, its products, customers, business models, and so on, in addition to discussing the actual revenue model. The first interview with a firm lasted approximately 90 minutes. It followed an open-ended interview structure in which the interviewee was able to talk freely about the topics raised. In the second and following interviews, I used more structured interview guidelines, based on the information gathered in the previous 
interview(s). These subsequent interviews focused on the revenue models in detail. I recorded all the interviews and personally transcribed them verbatim, using a word processing program. Thereafter, the complete transcripts were sent back to the interviewees for review. Mostly, the interviewees accepted the transcripts in the form in which I sent them. However, in some cases, the interviewees gave some minor comments related to the misspelling of a partner's name or to some particular wording. In addition to the face-to-face interviews, telephone and e-mail communication was used to collect further information, and to clarify inconsistent issues if necessary. These communications were also added to the case-study database. By comparing the interview data with other information gathered on the case firms, I conducted triangulation of the information [15].

In addition to the actual interviews, I have had several informal discussions with interviewees during seminars and in spare time. These informal discussions have been useful in terms of collecting further information and clarifying the business processes of the firms. In the data collection, I also used many types of secondary information such as press releases, websites of the firms, brochures, etc. to collect the kind of information that could validate the data gathered in the interviews.

The method utilized in the data analysis was content analysis. The analysis of the case data consisted of three concurrent flows of activity [15]: (i) data reduction, (ii) data displays, (iii) conclusion-drawing/verification. In (i) the data reduction phase, the data were given focus and simplified through compilation of a detailed case history of each firm. This is in line with Pettigrew [18], who suggests that organizing incoherent aspects in chronological order is an important step in understanding the causal links between events. Thereafter, on the basis of the interviews and other material collected from the case firms, I used tables to identify and categorize the unique patterns of each case under sub-topics derived from the research questions. In addition, I used checklists and event listings to identify critical factors related to the phenomena encountered [15]. In (ii) the data display phase, I arranged the relevant data drawn from the findings of the earlier phase into new tables. In (iii) the phase of conclusion-drawing and verification, I concentrated on identifying the aspects that appeared to have significance for this study. At this stage I noted regularities, patterns, explanations, and causalities related to the phenomena.

\section{FINDINGS}

\section{A. Benefits of using software rental}

The benefits to the case firms relating to software renting were mainly based on (i) the technical factors that made software renting cost-effective for a software provider and consequently for its customers, (ii) competitive advantages, in so far as software renting and SaaS were seen as forming a new way to sell the product, (iii) the low investment costs for customers in the rental model, and (iv) the positive network effect brought about by software renting. The interviewees from firms A, B, D, and E commented that in technical terms, SaaS brings several advantages to both the software provider and the customer, especially if the software is used in a public cloud. From the point of view of the software providers (firms A, D, and E), the SaaS model was seen as having achieved cost savings, as the software firms do not need to install the software on each customer's Intranet separately. It also decreases possible traveling costs related to installation, implementation, and after-sales support. The Vice President of Firm A commented on this aspect as follows:

"It brings cost savings. If we sell the Intranet version, it has be installed in the customer's premises, so it requires much more resources from us... in many cases, we need an employee who will go and meet the customer, install the software, implement the software, and give support. And then all the updates have to be delivered separately to each customer. In the cloud model, all this is centralized."

\section{The CEO of Firm D explained the same issue as follows:}

"We do not need to go and meet the customer and build the whole system for the customer's Intranet. Instead, we have an existing system within the cloud, and it makes the implementation much faster, and we can focus on the software and its functionalities."

Other benefits of the SaaS model included centralized development, maintenance, and expandability. This meant that the case firms knew that the customers were using the same version of the software, and by means of the public cloud, the case firm were able to bring in new options that were visible to all their customers immediately. These technical features consistently brought cost savings to the case firms. It made it possible to offer the software at a lower price in the rental mode than in the traditional licensing mode. In addition to cost savings, customers benefited from better scalability of the software, increased computing power and storage capacity, better flexibility, ease of use, and so on.

The case firms saw the SaaS and software renting as a new way to offer and deliver software products to their customers. They also anticipated that traditional licensing would disappear from the market in the future. The software firms were keen to follow the developments in the field, differentiate themselves from their competitors, and take advantage of the possibilities offered by SaaS and software renting. The Vice President of Firm A commented on this as follows:

"SaaS is something new, our competitors do not have a corresponding product, they have the traditional product that has to be installed in each computer using a CD-ROM."

The CEO of Firm B commented on their SaaS game offering in the following way:

"Of course it's a huge difference compared to the traditional way, if you think about playing via a PC. You 
have to have a certain PC, a certain operating system, a certain version of the operating system, certain programs, and it has to have enough memory, resources, etc."

All the case firms emphasized that the rental model was attractive to customers because of low initial investments. This made purchasing decisions much easier for the customer, bearing in mind the high investment costs associated with the traditional licensing fee. Hence, renting became a particularly attractive option for smaller customers who lacked a budget for costly licenses. In practice, this meant that in the rental model, customers were able to purchase the software without having to make special budgeting arrangements, undertake long decision-making processes, or apply for the approval of top management. All this implied more attractive pricing for the customer than with traditional licensing, and the possibility of cost savings. The CEO of Firm C commented as follows:

"Previously we only had a traditional licensing model an initial license fee plus an annual maintenance fee. However, we are now increasingly moving towards a license-rental model in which we charge a monthly rental fee. Then customers don't have to make an investment decision, the customer just pays the monthly rental fee. Then it is more like a cost, not an investment."

Interviewees from firms A, C, D, and E commented that software renting also enabled them to bring the product more quickly to the market. Smaller customers were able to buy it, and this helped the case firms to acquire good market visibility rapidly, thereby achieving a positive network effect. Interviewees from firms D and $E$ also mentioned that most of their customers showed little interest in the physical location of the software, or in the underlying technology. For them the important thing was that the software should work as it was designed to do. The Sales Manager of the Firm D explained this in the following manner:

"For some customers, it's all the same how it works. The main thing is that it solves the customer's business problem, and is easy to use. Usually they are relieved when they hear that they do not need to build up the whole infrastructure, they haven't even thought that this could be implemented in a cloud."

\section{B. Challenges to the use of software renting}

Software renting was the only option if a customer wished to use the software through a public cloud. Because of the advantages (mentioned above) of SaaS software delivery through the public cloud, firms tried to motivate their customers to adopt this model. However, achieving this was challenging, due to low readiness for new technologies on the part of some customers. The case firms reported that not all customers wished to use the software through the public cloud, with security concerns being given as the reason. This was a particular problem in the cases (firms A, $\mathrm{D}$, and $\mathrm{E}$ ) in which $\mathrm{B} 2 \mathrm{~B}$ software was rented through the public cloud. In the case of Firm $\mathrm{C}$, the software was sold and installed solely in the customer's private cloud, although it would have been technically possible to use it through the public cloud. For these customers, firms A, C, and D had a traditional licensing model available, i.e. with the customer buying the license for a workstation or using the software in its private cloud. Not surprisingly, security concerns varied between target industries depending on the sensitivity of the data stored and computed in the public cloud. For example, for Firm E, which sold 3D modeling software for the furniture industry, the impact of security concerns was less critical than for Firm $\mathrm{C}$, which offered risk management software for the financial industry. The CEO of Firms E mentioned that only about 10 percent of their customers were unwilling to rent the software and use it through the public cloud. In contrast, the CEO of Firm $\mathrm{C}$ explained the situation as follows:

"The software is related to the banks' core know-how, they don't let the information go outside the bank...this is related to their own cash flow, it's the greatest secret they possess".

The impact of security concerns in the SaaS model was also critical in some cases for customers of firms A and D. The Vice President of Firm A commented on this as follows:

"The target industry [tele-operators] is quite conservative. SaaS brings new opportunities but it doesn't mean that the customer is ready to accept it. Thus, we have to have the possibility to offer the product using an old revenue model."

For Firm A, another reason to sell a traditional license for a workstation was the unavailability of network connections (access to the cloud), in certain cases where a customer was in the process of building a new telecoms network. The Vice President of A also mentioned that they had to provide the option of software delivery via traditional licensing. Some of the customers were also suspicious of the connection speed and network capacity as being insufficient to run the software in the public cloud. This was particularly critical in the case of Firm B, which offered gaming services in a cloud. Firms A, C, and D offered customers a traditional license as an option. However, they tried to make software renting - especially through the public cloud - more attractive to the customer by having lower pricing for rented software than for the traditional license. This was mainly due to the fact that centralized customer service was found to be much easier and more cost effective (see also above). The Vice President of Firm A explained the matter as follows:

"We try to avoid traditional licensing by using a pricing model that makes the cloud model and software renting much cheaper for the customer"

However, Firm D saw it as good customer service to offer customers both options (software renting and a traditional license). Some of their customers had very strict rules, or IT polices that made it difficult to adopt new ways 
of buying and using software. In addition, Firm D pointed out that in technical terms, the product was the same for the public and the private cloud. The sales manager of firm D explained the policies on software provision as follows:

"We like to have both options available because both are sought by customers. We do not want to turn this into a restrictive issue... Technically there are no differences, so if the customer says that the product cannot be allowed out of their private cloud, then we will install it there."

\section{Factors impacting on the rental fee}

In four cases (firms A, B, C, and D), the rental fee was based on the number of users and/or the length of the agreement. The number of user impacted on the price, as the number of users correlated with the capacity required for data storage and computing power. In addition, a large number of users made the installation (Firm C) and customer support more complex and time consuming. The duration of the agreement varied depending on the product. It was from three months to three years in the case of B2B, but in the case of video games the duration was only from 24 hours to one month (Firm B). At the end of the period, the firms negotiated a new agreement with customers for a fixed period. The length of the agreement impacted on the rental fee, in such a way that a longer agreement reduced the monthly fee for the software. Firm E had previously applied an annual fee, but changed it to a monthly fee, as annual fees proved to be too high and unattractive for smaller customers. However, it was in the interest of the case firms to have as long an agreement as possible, as this would commit customers to using their products, and lessen their workload in relation to customers. The sales manager of Firm A commented on this as follows:

"If there are a larger number of users, let's say dozens, we want to have an agreement for at least three to six months. We don't want to do be doing extra work for nothing."

Two of the firms also priced the rental fee according to the functionalities included in the software. Firm E offered their 3D modeling software in four different packages. The first package included the basic functionalities needed to run the program; then, if a customer wished, the firm was able to add additional functionalities later on. Firm $\mathrm{C}$ used a similar strategy with its risk management software, with the rental charge being based on the functionalities that the customers wished to include. The CEO of Firm $\mathrm{C}$ explained this as follows:

"All the customers have parallel needs, but they do not necessarily need all the functionalities. So the customers pay only for what they need, and later on they can add new functionalities. We only provide a new license key, and the new functionalities are available immediately."

Firm E, which modeled furniture elements for their 3D software, also priced the rental charge according to the quantity of furniture elements included in the software. The software allows new furniture elements to be added later, with a corresponding increase in the rental charge. The CEO of the firm explained this as follows:

"When the system is activated, we can bring in new content all the time. The customer may start with one furniture range, but they may have ten ranges, or they may have repeats of ranges that they want to include later on."

The rental model allowed flexible payment options for customers, and these make the service more attractive than the traditional way of buying games from a store. The CEO of Firm B expressed this as follows:

"This revenue model allows very interesting pricing strategies. Instead of buying the game from a store, this makes it possible to rent the game for a day...or the game can be a part of a games package that can be used for a month."

However, managers of the firms operating in the B2B market (Firms A, C, D, E) emphasized that the content of the rental agreement is always negotiated with each customer separately. The sales manager of Firm C put it this way:

"If we have a major customer who wants our software for their offices around Europe... of course we will discuss the amounts for the installations and the usage. It is the same as if you were buying one car or ten cars. You will get a better offer from ten cars. In our business, it works the same way. In addition, the number of functionalities has an impact on the final price. These all have to be negotiated with the customer."

\section{The CEO of the Firm A commented:}

"Of course we can rent the software for a shorter time if a customer needs it, for example for a short project -that is possible. However, it might become more expensive for the customer because the initial costs are the same for us, regardless of the rental time. But if there is a need for it, we are ready to discuss it with the customer."

\section{DISCUSSION}

In relation to the first research question, the findings of this study indicate that the benefits of software renting derive from both technical advantages and competition strategies. First of all, software rental through the public cloud made software renting easier from a technical point of view, since the firms could use centralized delivery of software to their customers. Centralized software delivery and maintenance decreased the transaction costs and brought savings. This method also protected their products against perishability (see [21]), as the case firms were able to update new versions of the software in a centralized manner. In this way, all the customers using the public cloud received these updates immediately. 
Secondly, software rental and SaaS gave competitive advantages to the case firms. By using a suitable combination of the new revenue and delivery model, they were able to differentiate themselves from other competitors and to offer something new to the customer. Thus, software renting and SaaS can be seen as a substitute for the old licensing model in which software was bought by paying an expensive fee for a license, with installation thereafter on a certain number of computers. This is in line with Porter's [21] notion that substitutes gives competitive advantages if they perform the same task within a lower price range than the original. Furthermore, switching costs were very low for the customer if they moved from traditional licensing to software renting.

Thirdly, software renting made the case firms' products available for smaller customers, who would not have been able to pay for the software by the traditional licensing method. This method also provided added value to customers in terms of flexibility. Shifting capital investment onto operational costs enabled them to start using the software without special budgeting, or without having to obtain the approval of top management. This increased the case firms' competitive advantage, since they were now able to widen their customer segment from large corporations to small and medium-sized firms. In addition, software renting made it possible for customers to predict the actual costs of the software. Thus, in the renting model there were no hidden costs (see [21]). This finding expands the list of benefits to customers obtainable via software renting, as set out by Choudhary et al. [4] SaaS also made software easier to use, and this, in conjunction with the rental option, increased customers' willingness to try the software and determine whether it solved their business problems. Altogether, this increased the positive network effect, bearing in mind also that the investment costs are low, and that the product is available through the Internet. Interestingly, the benefits of software renting to the customer - as identified by Choudhary et al. [4] - seem in fact to be disadvantageous for the software vendors, for example, regarding the utility of software for short-term projects.

Concerning the second research question, the problems in the use of software renting were mainly related to cases in which the software was rented through the public cloud. Usage of the public cloud seems to decrease customers' willingness to rent software, with concerns involving data security or accessibility in the public cloud. This was challenging to the case firms, since software renting was less profitable if the software was rented through the customer's private cloud (given that the private cloud method increases transaction costs related to installation and updating). Because of the security concerns of the customers, some firms also offered traditional licensing in addition to software renting. This option persuaded customers who wanted to use their own private cloud to run the software. In addition, by offering both options, the firms demonstrated their commitment to good customer service. This finding implies that the lack of trust in the public cloud [12] is indeed an important challenge in software renting, and it illustrates the negotiating power of customers $[19,21]$. In line with economic theories of renting $[2,8]$ the findings also demonstrate that if the product is needed for a long time, and if it plays a key role in a firm's business, customers are more inclined to buy than to rent. In that way they can secure access to the software and to the important knowledge stored in their data center.

In relation to the third research question, the case firms used various pricing strategies. The factors that impacted on the rental fee were: 1) the length of the rental agreement, 2) the number of users, 3) the functionalities included in the software, 4) the size of the customer, and 5) the elements included in the software. This finding shows the ways in which the factors impacting on the traditional license fee were transformed into the rental fee. Thus, there was no "list price" as such, since the price was always the sum of different options and in many cases, negotiated separately with each customer. The findings demonstrate that the case firms tried to negotiate with the customers' agreements of maximum duration. Long agreements protected the firms against the low switching costs available to customers. Although the customers' low switching costs from traditional software licensing to software renting were beneficial to the case firms, there was always the threat that the low switching cost would cause the customer to consider switching to another vendor. This is in accordance with Choudhary's [3] findings that software renting has low switching costs, and that customers can easily change a software vendor if they are not satisfied with the quality or price of the software. Because all the case firms were relatively small-sized vendors, the negotiating leverage of the customers affected the vendors' pricing strategies and revenue models. In many cases, the firms commented that the rental agreements were negotiated with customers, with the length of the agreement being dependent on these negotiations. However, all the case firms were operating in very niche segments in which the competition was not so intense. Thus, there was not in fact that much rivalry among competitors [21], and this gave the case firms some protection against the negotiating leverage of the customers.

\section{CONCLUSIONS}

This study contributes to research on software renting in four respects. First of all, it validates and expands on earlier work related to software renting $[3,4,9,26]$ by providing empirical support for their economic models. Secondly, it reveals the competitive advantages and disadvantages related to software renting from the software vendors' point of view, in contrast to previous research focusing mainly on the benefits to customers. Thirdly, this study contributes to knowledge of software renting in cloud computing, bearing in mind that cloud computing constitutes a new strategic tool for the delivery of software products in the market. Fourthly, it demonstrates the variety of pricing strategies used in defining the rental charge.

The main findings of this study imply that strategically speaking, software renting can be seen as a substitute for traditional software licensing. It tends to decrease prices, and it can offer new features that assist in 
differentiating software vendors from their competitors. The low initial costs in software renting make the software available for smaller customers who might not otherwise be able to invest in a costly software license. Thus, by using software renting, firms can widen their customer segment and achieve a positive network effect. However, the switching costs from one software renter to another are low and this can make it difficult for the vendors to hold onto their customers.

The findings also show that the smaller software renters have to take into account the negotiating power of large customers. In many cases this led the firms studied to give customers the option of obtaining their products via traditional licensing, or through a private cloud. Larger firms may also have more overall negotiating power to secure better rental agreements. The study also implies that between software vendors and customers there are conflicting interests. The software vendors sought to protect against low switching costs by trying secure agreements of maximum duration. Conversely, short agreements were more beneficial to the customers, as they were not tied to particular software for a long period.

From a managerial point of view, software renting and cloud computing make it possible for software vendors to expand their business opportunities. However, although this is a highly promising way of distinguishing oneself from the competition, the entry barriers in the cloud business are relatively low. This means that in the future there may well be an increase in new entries - and in fact, a similar process occurred in e-commerce during the IT boom [20]. Thus, software vendors will be obliged to protect their business against newcomers and to develop their software to respond to the changing needs of the market. This will require flexibility and ongoing recognition of new business opportunities, given the unpredictabilities in the development of the software market and the competition within it.

In the end, it is good to note that the findings of this study cannot be generalized due to the methodological circumstances. However, the findings can be used for the further quantitative testing.

\section{REFERENCES}

[1] Armbrust et al., 2010. A view of cloud computing. Communication of the ACM 53 (4), 50-58.

[2] Bulow, J.I., 1982. Durable-Goods Monopolists. Journal of Political Economy 90 (2), 314-332.

[3] Choudhary, V., 2007. Comparison of Software Quality Under Perpetual Licensing and Software as a Service. Journal of Management Information Systems 24 (2), 141-165.

[4] Choudhary, V. Tomak, K., Chaturvedi, A., 1998. Economic Benefits of Renting Software. Journal of Organizational Computing and Electronic Commerce 8 (4), 277-305.

[5] Gens, F., 2009. Defining "Cloud Services" -an IDC update. IDC exhanges. blogs.idc.com/ie/?p=422.
[6] Eisenhardt, K.M., 1989. Building theories from case study research. Academy of Management Review 14 (4), 532-550.

[7] Ferrante, D., 2006. Software Licensing Models: What's Out There? IT Professional 8 (6), 24-29.

[8] Flath, D., 1980. The Economics of Short-term Leasing. Economic Inquiry 18 (2), 247-259.

[9] Gurnani, H., Karlapalem, K., 2001. Optimal pricing strategies for Internet-based software dissemination. Journal of the Operational Research Society 52 (1), 64-70.

[10] Huang, K-W., Wang, M., 2009. Firm-Level Productivity Analysis for Software as a Service Companies. Proceedings of the ICIS 2009.

[11] Hugos, M.H., Hulitzky, D., 2011. Business in the Cloud: What Every Business Needs to Know About Cloud Computing. John Wiley \& Sons, Inc.

[12] Khan, K.M. and Malluhi, Q., 2010. Establishing Trust in Cloud Computing. IT Professional 12 (5), 20-27.

[13] Liebowitz, S.J., Margolis, S.E., 1994. Network Externality: An Uncommon Tragedy. The Journal of Economic Perspectives 8 (2), 133-150.

[14] Louridas, P., 2010. Up in the Air: Moving Your Applications to the Cloud. IEEE Software 27 (4), 6-11.

[15] Miles, M.B., Huberman A.M., 1994. Qualitative Data Analysis: An Expanded Sourcebook. California: Sage Publications.

[16] Nambisan, S., 2002. Software firm evolution and innovationorientation. Journal of Engineering and Technology Management 19 (2), 141-165.

[17] Ojala, A., Tyrväinen, P., 2011. Developing Cloud Business Models: A Case Study on Cloud Gaming. IEEE Software 28 (4), 42-47.

[18] Pettigrew, A.M., 1990. Longitudinal Field Research on Change: Theory and Practice. Organization Science 1 (3), 267-292.

[19] Porter, M., 1979. How Competitive Forces Shape Strategy. Harvard Business Review 57 (2), 137-145.

[20] Porter, M., 2001. Strategy and the Internet. Harvard Business Review 79 (3), 62-78

[21] Porter, M., 2008. The five competitive forces that shape strategy. Harvard Business Review 86 (1), 78-93.

[22] Sainio, L-M., Marjakoski, E., 2009. The logic of revenue logic? Strategic and operational levels of pricing in the context of software business. Technovation 29 (5), 368-378.

[23] Sundararajan, A., 2004. Nonlinear Pricing of Information Goods. Management Science 50 (12), 1660-1673.

[24] Stake, R.E., 1995. The art of case study research, Sage Publications.

[25] Schweizer, L., 2005. Organizational Integration of Acquired Biotechnology Companies into Pharmaceutical Companies: The Need for a Hybrid Approach. Academy of Management Journal 48 (6), 1051-1074.

[26] Varian, H., 2000. Buying, Sharing and Renting Information Goods. The Journal of Industrial Economics 48 (4), 473-488.

[27] Waters, B., 2005. Software as a service: A look at the customer benefits. Journal of Digital Asset Management 1, 32-39.

[28] Yin, R.K., 2009. Case study research: Design and methods. CA: SAGE Publications. 